\title{
Calculation Method for Forced-Air Convection Cooling Heat Transfer Coefficient of Multiple Rows of Memory Cards
}

\author{
Takayuki Atarashi1,2*, Tetsuya Tanaka ${ }^{1}$, Shigeyasu Tsubaki ${ }^{3}$, Shigeki Hirasawa ${ }^{2}$ \\ ${ }^{1}$ Hitachi, Ltd., Infrastructure Systems Company, Toshima, Tokyo, Japan \\ ${ }^{2}$ Department of Mechanical Engineering, Kobe University, Kobe, Japan \\ ${ }^{3}$ Hitachi, Ltd., Information and Telecommunication Systems Company, Hatano, Japan \\ Email: "takayuki.atarashi.of@hitachi.com
}

Received 1 July 2014; revised 1 August 2014; accepted 30 August 2014

Copyright (C) 2014 by authors and Scientific Research Publishing Inc.

This work is licensed under the Creative Commons Attribution International License (CC BY).

http://creativecommons.org/licenses/by/4.0/

\section{(c) (i) Open Access}

\begin{abstract}
Forced-air convection cooling of high-power electronic devices is widely used, but it has a problem that a rise in temperature of the air used to cool the upstream devices decreases the cooling capability for the downstream devices. In this study we made an experimental apparatus including a memory card array and measured the effect of the rise in temperature of the air on the heat transfer coefficient of the memory cards that were downstream in the air flow. Using these measurements, we devised a simple calculation model, called the thermal diffusion layer model, to calculate the heat transfer coefficient of multiple rows of memory cards. The rise in temperature of downstream memory cards due to higher temperature air can be evaluated with a parameter representing the delay of thermal mixing for air. The heat transfer coefficient calculated with the thermal diffusion layer model agreed with our experimental results.
\end{abstract}

\section{Keywords}

Forced Convection, Heat Transfer Performance, LSI Cooling, Memory Array

\section{Introduction}

The heat density of high-load electronics, such as high-performance servers and the inverters used in vehicles, has been increasing as a result of higher processing speeds and higher power outputs. Focusing on the heat den-

"Corresponding author.

How to cite this paper: Atarashi, T., Tanaka, T., Tsubaki, S. and Hirasawa, S. (2014) Calculation Method for Forced-Air Convection Cooling Heat Transfer Coefficient of Multiple Rows of Memory Cards. Journal of Electronics Cooling and Thermal Control, 4, 70-77. http://dx.doi.org/10.4236/jectc.2014.43008 
sity of high-performance server-CPU (Central Processing Unit) modules, the trend in development since 2000 has been away from bi-polar devices and toward low-power-consumption CMOS (Complementary Metal Oxide Semiconductor) devices. However, continued demand for higher performance has reversed the trend, and the heat density of CPU modules has begun to rise again. The method used to cool electronic devices depends on the heat generation level and the operating environment, whereas the available methods include natural convection cooling [1], forced-air convection cooling, heat pipe cooling [2], and liquid cooling. Forced-air convection cooling is the most often used because of its practical advantages in cost, installation, and maintenance. For these reasons, we have been developing a forced-air convection cooling structure to cool multiple LSI (Large Scale Integration) packages and memory arrays that are mounted on a flat wiring board in electronic equipment. A parallel flow method is used in which the LSI packages and arrays are cooled sequentially by air that flows parallel to the wiring board. A problem with this method is that the heat from the upstream devices raises the temperature of the cooling air so that its cooling capability is decreased remarkably for the downstream devices. Yanagida [3] analyzed the temperature distribution of air after heating devices and proposed a method that used the thermal diffusion layer model to calculate temperature distribution of LSI packages on a printed wiring board. The authors developed highly efficient cooling methods using inclined strip fins and air-jet cooling methods that were not affected by an increase in the temperature of the cooling air [4] [5]. Kheirandish et al. [6] analyzed forced convective laminar flow in a channel with a heated obstacle attached to one wall. Recently, Nakayama [7] reviewed various cooling methods of electronic devices. In this work we study forced-air convection cooling of multiple rows of memory cards placed on a printed wiring board. Each memory card has many DRAM-LSIs (Dynamic Random Access Memory LSIs) mounted on both sides (Figure 1). Some studies [8] on this topic reported on the cooling performance of a single memory card, but very few have dealt with rows of memory cards.

In this study, we made an experimental memory card apparatus with four rows in the flow direction and eight rows in the parallel direction. We measured the effect of a rise in the temperature of the air on the heat transfer coefficient of the downstream memory cards. Using these measurements, we then devised a simple model for calculating the heat transfer coefficient of multiple rows of memory cards. We compared the calculation and experimental results and found their values to be in good agreement.

\section{Experimental Apparatus}

Figure 2 shows the experimental apparatus. The test section is placed in an acryl duct. The outside of the duct is thermally insulated with 50-mm-thick of glass wool. Cooling air from a blower flows into the test section after flow rate $G$ and temperature $T_{\text {ain }}$ are measured in chambers 1 and 2. Figure 3 shows the test section. Memory cards are four rows in the flow direction and eight rows in the parallel direction in the duct. Each memory card has five model-LSIs mounted on both sides. In the heat transfer experiment, any one of the four rows in the flow direction is replaced with heating model-LSIs and others are non-heating model-LSIs. The heating model-LSI is aluminum block with a stainless steel heater with heating rate $Q$ of each model-LSI is $0.2 \mathrm{~W}$. The surface temperature $T_{\mathrm{s}}$ of the heating model-LSI was measured with a T-type thermocouple, and the heat transfer coefficient $h$ was obtained using Equation (1).

$$
h=\frac{Q}{A_{\mathrm{S}}\left(T_{\mathrm{S}}-T_{\text {ain }}\right)}
$$

Here, $T_{\text {ain }}$ is the inlet air temperature, and $A_{\mathrm{s}}$ is the surface area. Also, the surface temperatures of non-heating model-LSIs were measured with thermocouples. In this paper, the number of rows of memory cards in the flow

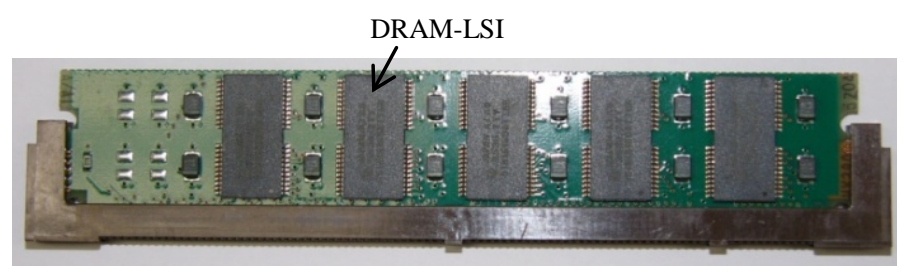

Figure 1. Memory card. 


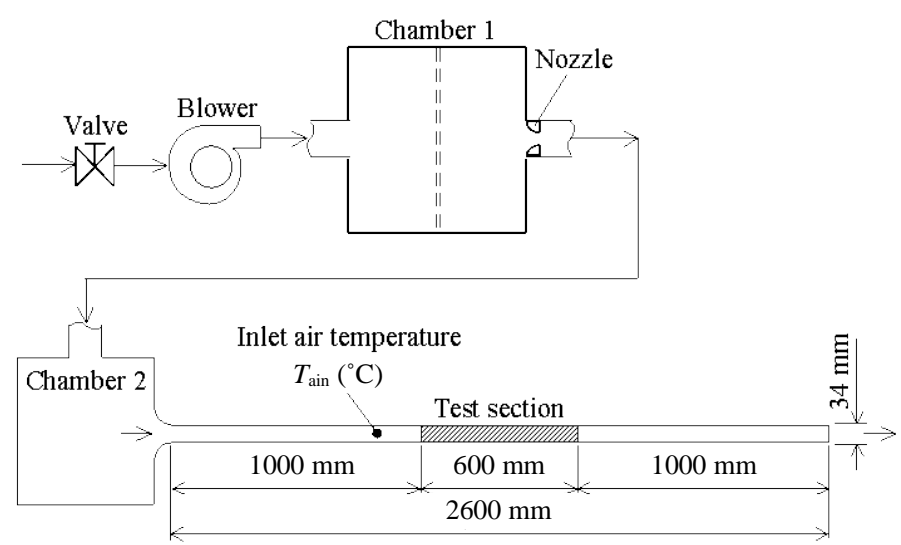

Figure 2. Experimental apparatus.

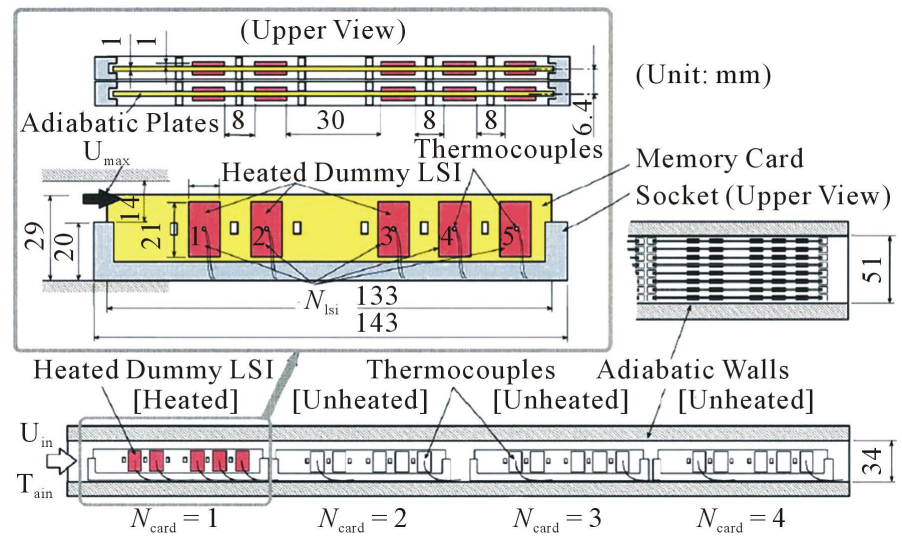

Figure 3. Test section of memory card array.

direction is expressed as $N_{\text {card }}=1-4$ and number of rows of the memory LSIs in each card is expressed as $N_{\text {lsi }}=$ $1-5$.

\section{Experimental Results of Temperature Rise of LSIs and Thermal Diffusion Layer Model}

First, we measured the temperature rise of non-heating LSIs when they were heated by the air flow from the upstream memory card. Figure 4 shows the experimental results of the temperature rise $\Delta T_{a}$ of the non-heating LSIs at the $N_{\mathrm{lsi}}=1$ or 5 position on the downstream memory cards at the $N_{\text {card }}=2$ - 4 positions when the heating memory card was placed at the $N_{\text {card }}=1-3$ positions. Figure 5 shows the parameter $\alpha_{t}=\Delta T_{a} / \Delta T_{m}$ which means the delay of thermal mixing in air, $\Delta T_{a}$ is the measured temperature rise of the non-heating LSI, and $\Delta T_{m}$ is the calculated temperature rise of completely mixed air. The temperature rise $\Delta T_{m}$ was calculated with the air flow rate and heating rate of the LSI. When the air is not mixed completely, $\alpha_{t}$ is larger than 1 . The parameter $\alpha_{t}$ decreases downstream and comes close to 1 at all heating memory card positions, $N_{\text {card. }}$.

Figure 6 shows the relation between the delay of thermal mixing in air $\alpha_{t}$ and the distance from the heat source $X$ for various heating positions and flow velocities. We can obtain the relationship between the parameter $\alpha_{t}$ and the distance from the heat source $X$, similar to the thermal diffusion layer model proposed by Yanagida [3].

Figure 7 shows the thermal diffusion layer model for our experimental apparatus. The dimensions of the heating LSI were as follows: height $a=1 \mathrm{~mm}$, width $b=21 \mathrm{~mm}$, and length $L=10 \mathrm{~mm}$. The area of the thermal diffusion layer $A$ is wider than the front area of the LSI $(a \times b)$ by the thermal diffusion thickness $\delta_{t}$. Hence, we can write $A=(a \times b)+(2 a+b) \times \delta_{t}$. The delay in thermal mixing in the air flow $\alpha_{t}=\Delta T_{a} / \Delta T_{m}$ can be calculated with $A_{0} / A$, where $A_{0}$ is the cross-sectional area of the air duct. The thermal diffusion thickness $\delta_{t}$ is proportional 

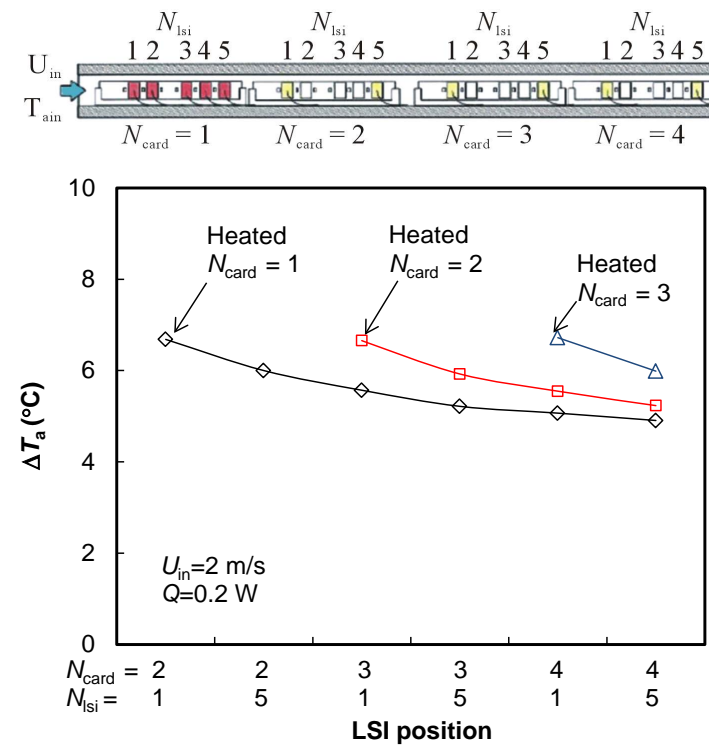

Figure 4. Temperature rise of LSIs.

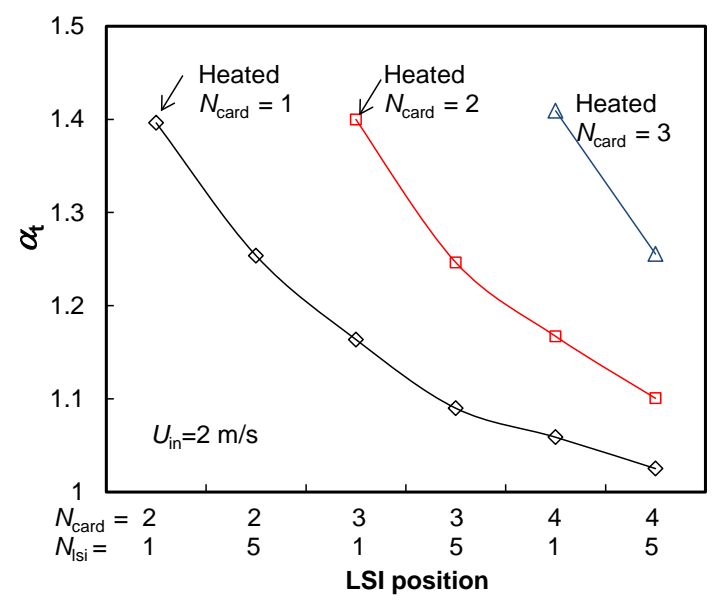

Figure 5. Delay of thermal mixing in air.

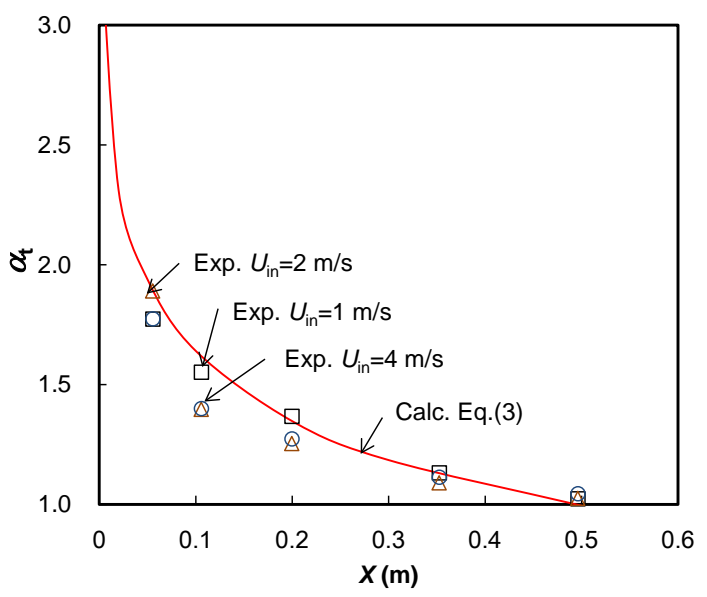

Figure 6. Relation between delay of thermal mixing in air and distance from heat source. 


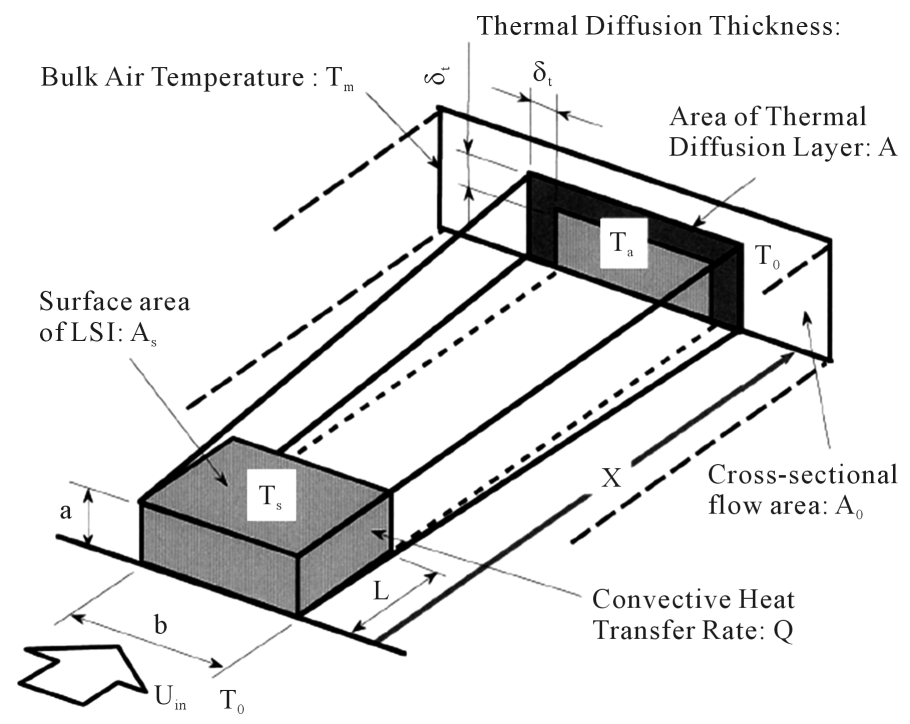

Figure 7. Thermal diffusion layer model.

to $\sqrt{X}$, and the proportionality constant is obtained using our experimental data shown in Figure 6, as follows:

$$
\delta_{t}=0.0032 \sqrt{X}
$$

The parameter $\alpha_{t}$ and the distance from the heat source $X$ have following relationship using Equation (2):

$$
\alpha_{t}=\frac{A_{0}}{A}=\frac{A_{0}}{a b+0.0032(2 a+b) \sqrt{X}}
$$

Calculation results with Equation (3) agree with the experimental results in Figure 6.

\section{Experimental Results of Heat Transfer Coefficient and Comparison with Calculation Using Thermal Diffusion Layer Model}

Figure 8 shows the experimental results of the heat transfer coefficient $h$ of LSIs at the $N_{\mathrm{lsi}}=1$ - 5 positions on the memory card at the $N_{\text {card }}=1$ position with a change in the inlet air velocity $u_{\text {in }}$ when the heating memory card was placed at the $N_{\text {card }}=1$ position. We see that the heat transfer coefficient $h$ of the downstream LSIs is lower than that of the upstream LSIs, because of the temperature rise in the air flow.

The heat transfer coefficient $h_{\mathrm{S}}$ on a flat surface of a single LSI can be calculated with the following equations [9] by using the Reynolds number, $\operatorname{Re}=\frac{u_{\max } L}{v_{\mathrm{a}}}$ :

$$
h_{\mathrm{S}}=0.664 \operatorname{Re}^{0.5} \operatorname{Pr}_{\mathrm{a}}^{0.33} \frac{\lambda_{\mathrm{a}}}{L}
$$

Here, $u_{\max }$ is the air velocity above the LSI's surface, $L$ is the length of LSI, $v_{\mathrm{a}}$ is the dynamic viscosity of air, $\operatorname{Pr}_{\mathrm{a}}$ is the Prandtl number of air, and $\lambda_{\mathrm{a}}$ is thermal conductivity. The broken line in Figure 8 shows the result of calculation $h_{\mathrm{S}}$ using Equation (4), and it agrees with the experimental results of the $N_{\mathrm{lsi}}=1$ data.

Next, we calculated the heat transfer coefficient $h_{\mathrm{N}}$ coupled with the temperature rise in air using $\alpha_{t}$. The heat transfer coefficient $h_{\mathrm{N}}$ can be calculated with the following equation:

$$
h_{\mathrm{N}}=\frac{1}{\frac{A_{\mathrm{s}}}{G C_{\mathrm{p}}} \sum_{i=1}^{N-1} \alpha_{t, i}+\frac{1}{h_{\mathrm{s}}}}
$$

Here $G$ is the air flow rate, and $C_{\mathrm{p}}$ is the specific heat of air. The solid lines in Figure 8 show the results of the 
calculation $h_{\mathrm{N}}$ with Equation (5), and they agree with the experimental results of the $N_{\mathrm{lsi}}=2-5$ data.

Figure 9 and Figure 10 show the experimental results of the heat transfer coefficient $h$ of the LSIs at the $N_{\text {lsi }}$ $=1-5$ positions on the memory cards at the $N_{\text {card }}=2$ and 4 positions with a change in the inlet air velocity $u_{\text {in }}$ when the heating memory card was placed at the $N_{\text {card }}=2$ and 4 positions. The heat transfer coefficient $h$ in Figure 9 and Figure 10 is almost same as that in Figure 8, and the calculations $h_{\mathrm{S}}, h_{\mathrm{N}}$ using Equations (4) and (5) agree with the experimental results.

Figure 11 shows the experimental results of the overall heat transfer coefficient $h_{\text {overall }}$ of the LSIs at the $N_{\mathrm{lsi}}=$ 1 and 5 positions on the memory cards at the $N_{\text {card }}=2$ and 4 positions when all memory cards at the $N_{\text {card }}=1$ - 4 positions are heating. The results of the calculation with Equation (5) agree with the experimental results. Therefore, the thermal diffusion layer model of Equation (5) is a precise calculation of heat transfer coefficient of multiple rows of memory cards, despite that it is very simple. Our proposal of the thermal diffusion layer model of Equation (5) is thus very practical.

\section{Conclusions}

We made an experimental apparatus including a memory card array and measured the effect of a rise in the temperature of air on the heat transfer coefficient of memory cards at downstream positions in the air flow. Using these measurements, we proposed a simple calculation model of the heat transfer coefficient of multiple rows of memory cards. The following results were obtained.

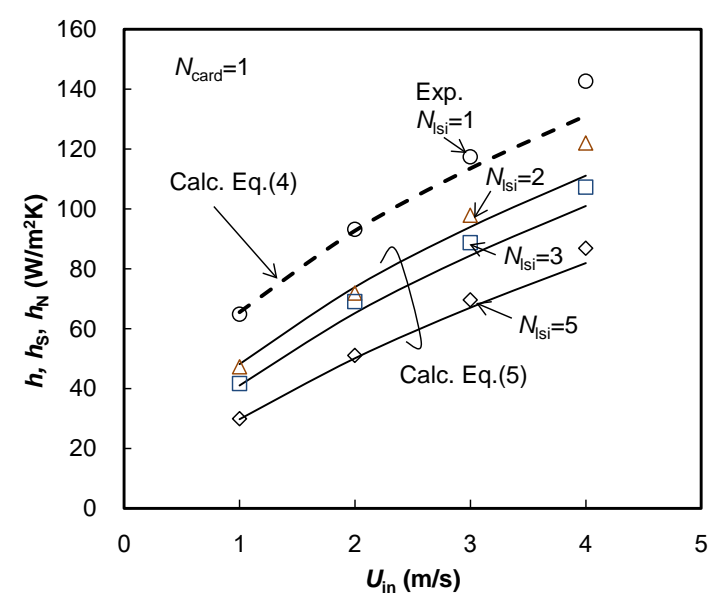

Figure 8. Heat transfer coefficient of LSIs $N_{\text {lsi }}=1-5$ on memory card $N_{\text {card }}=1$.

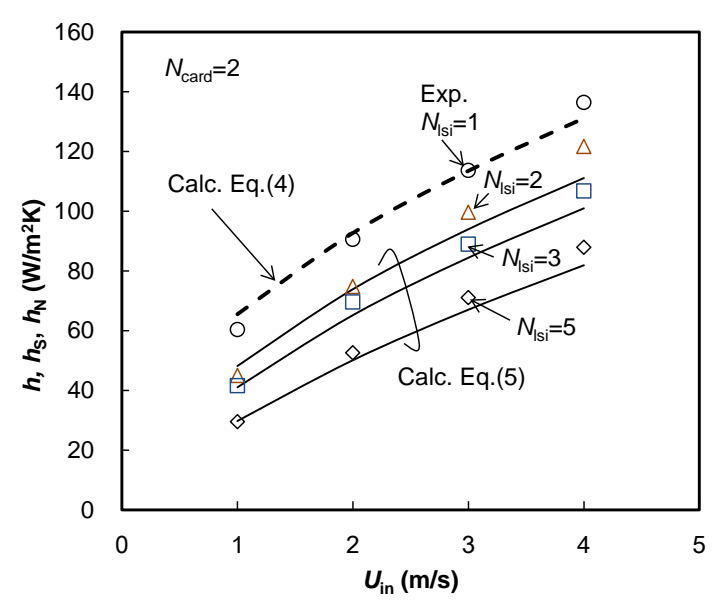

Figure 9. Heat transfer coefficient of LSIs $N_{\mathrm{lsi}}=1-5$ on memory card $N_{\text {card }}=2$. 


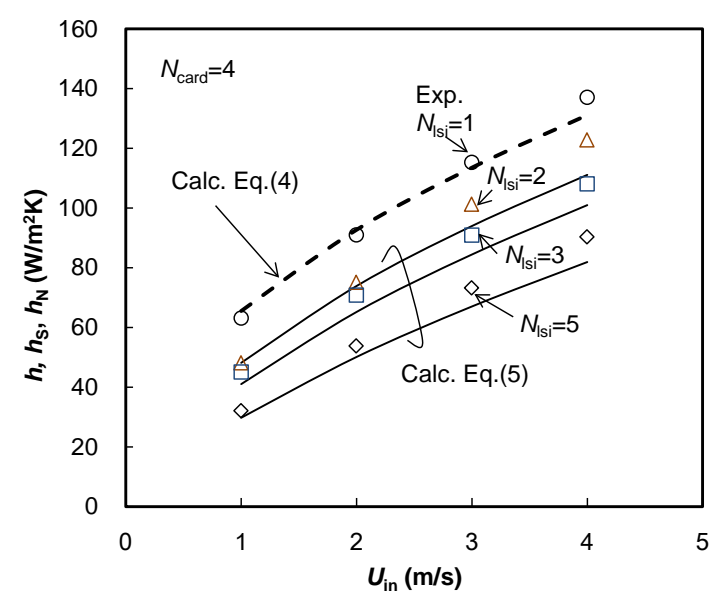

Figure 10. Heat transfer coefficient of LSIs $N_{\mathrm{lsi}}=1$ 5 on memory card $N_{\text {card }}=4$.

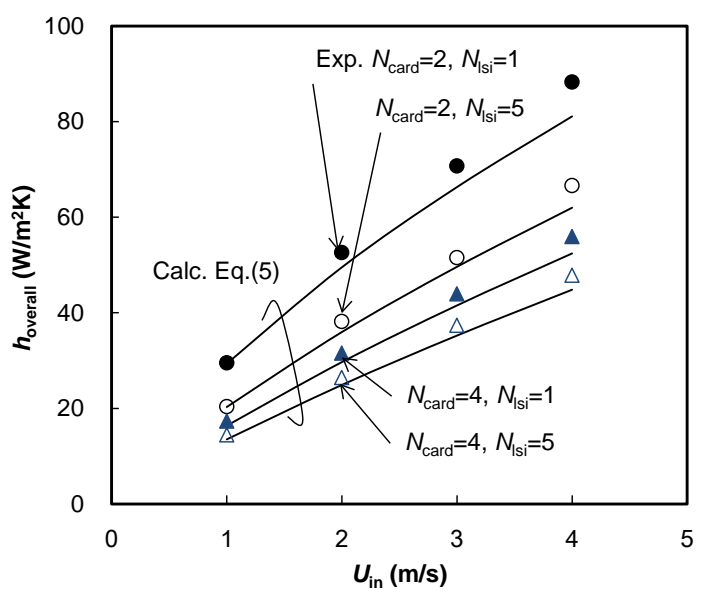

Figure 11. Overall heat transfer coefficient.

1) The rise in temperature of the downstream LSI resulting from a temperature rise in the air heated by an upstream heating source can be evaluated with a parameter called the delay of thermal mixing in air, $\alpha_{t}$. The parameter $\alpha_{t}$ decreases downstream and comes close to 1 at a large distance from the heat source $X$ and $\alpha_{t}$ does not depend on the heating position or flow velocity.

2) The heat transfer coefficient coupled with the rise in temperature of the air through the parameter $\alpha_{t}$ can be calculated with Equation (5) and the thermal diffusion layer model. The calculation agreed with the experimental results. There results indicate that the thermal diffusion layer model is a simple and precise method of calculating heat transfer coefficient of multiple rows of memory cards.

\section{References}

[1] Nakazato, N., Hirasawa, S. and Mato, T. (1998) Natural Convection Cooling in Vertical Finned Plates in a Cabinet for Communication Equipment. IEICE Transactions on Electronics, 3, 421-426.

[2] Toyoda, H. and Kondo, Y. (2013) Effect of Non-Condensable Gas Leakage on Long Term Cooling Performance of Loop Thermosyphon. Journal of Electronics Cooling and Thermal Control, 3, 131-135. http://dx.doi.org/10.4236/jectc.2013.34014

[3] Yanagida, T. (1988) A Calculation Method for Temperature Distribution of IC Packages on a Printed Wiring Board. Transactions of JSME, Series B, 54, 1730-1735.

[4] Atarashi, T., Hatada, T. and Daikoku, T. (1994) Forced Air Cooling Radiators for Electronic Equipment. Transactions of JSME, Series B, 60, 620-626. 
[5] Atarashi, T., Tanaka, T. and Tsubaki, S. (2012) Optimization of Heat Sinks with Plate Fins in Air-Jet Cooling. Proceedings of 3rd International Forum on Heat Transfer (IFHT2012), Paper No. 150.

[6] Kheirandish, Z., Nassab, S.A.G. and Vakilian, M. (2013) Second Law Analysis of Forced Convective Cooling in a Channel with a Heated Wall Mounted Obstacle. Journal of Electronics Cooling and Thermal Control, 3, 101-110. http://dx.doi.org/10.4236/jectc.2013.33012

[7] Nakayama, W. (2014) Max Jakob Award Paper-Heat in Computers: Applied Heat Transfer in Information Technology. Transaction of ASME, Journal of Heat Transfer, 136, Article ID: 013001.

[8] Yoneda, N., Arita, J. and Hosokawa, K. (1999) Thermal Analysis of Memory Module. Proceedings of JSME Thermal Engineering Conference, 31-32.

[9] Holman, J.P. (1981) Heat Transfer (International Student Edition). McGraw Hill International Book Co. 
Scientific Research Publishing (SCIRP) is one of the largest Open Access journal publishers. It is currently publishing more than 200 open access, online, peer-reviewed journals covering a wide range of academic disciplines. SCIRP serves the worldwide academic communities and contributes to the progress and application of science with its publication.

Other selected journals from SCIRP are listed as below. Submit your manuscript to us via either submit@scirp.org or Online Submission Portal.
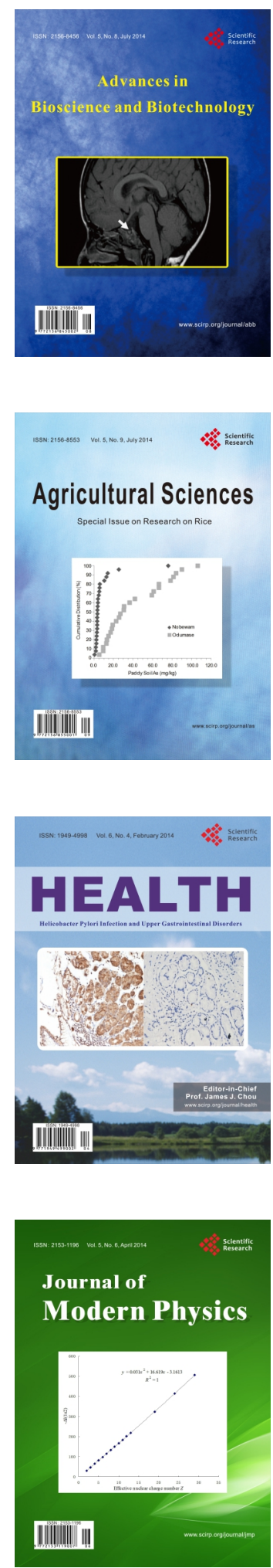
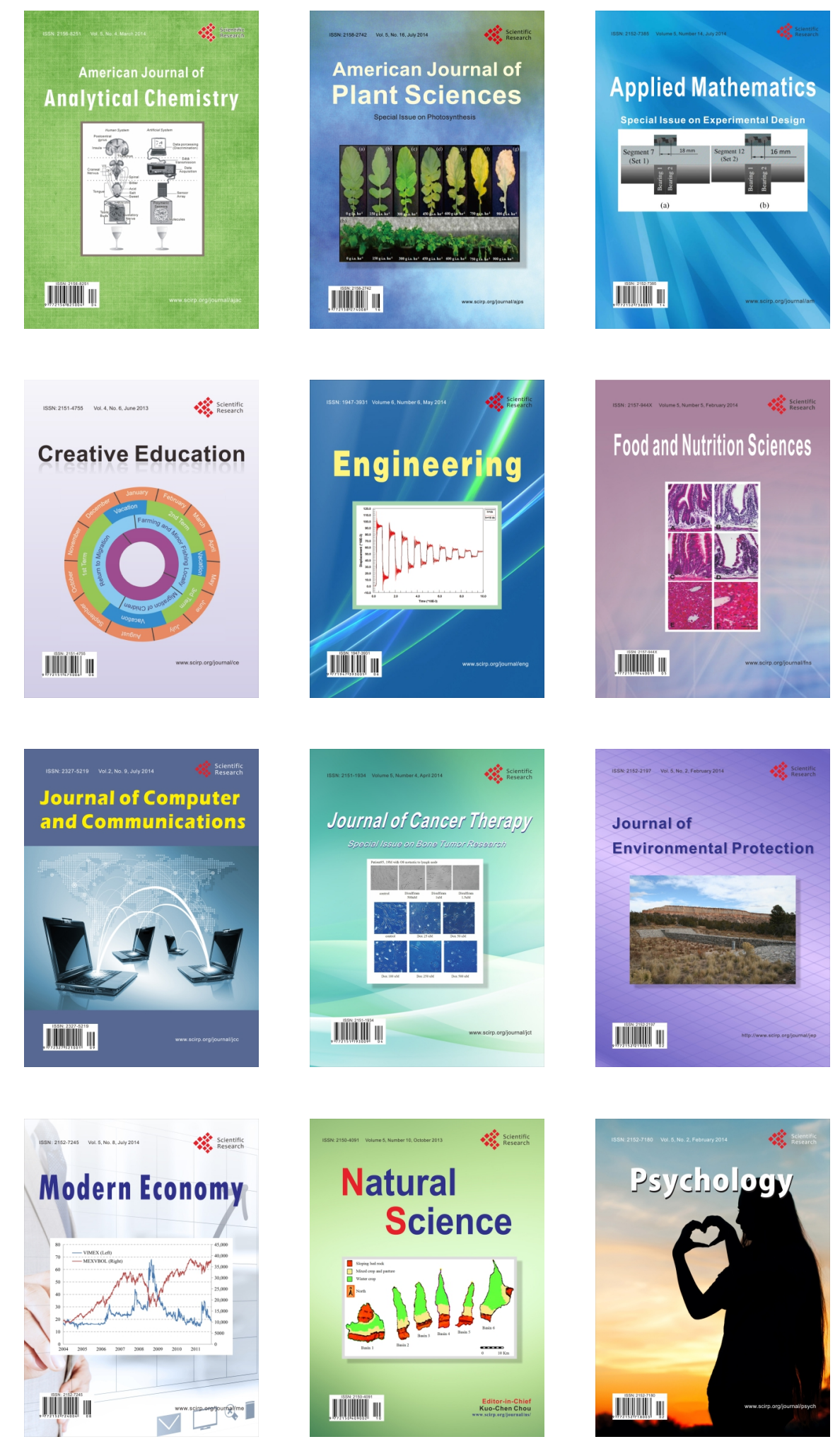